Supplementary Information

\title{
Preclinical evaluation of a fluorine-18 labeled probe for detection the expression of PSMA level in cancer
}

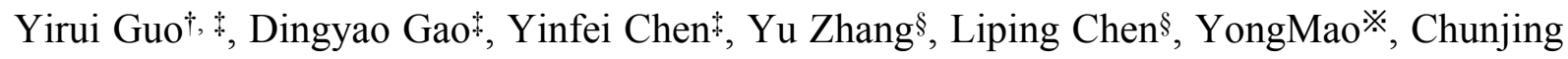
$\mathrm{Yu}^{*}, \dagger, \S$, Lin Qiu ${ }^{\ddagger}$ and Jianguo Lin ${ }^{*}+$

tWuxi School of Medicine, Jiangnan University, Wuxi 214122, P R China.

‡NHC Key Laboratory of Nuclear Medicine, Jiangsu Key Laboratory of Molecular Nuclear Medicine, Jiangsu Institute of Nuclear Medicine, Wuxi 214063, P. R. China.

§Department of Nuclear medicine, Affiliated Hospital of Jiangnan University, Wuxi 214062, P. R. China.

※Department of Oncology, Affiliated Hospital of Jiangnan University, Wuxi 214062, P. R. China.

Corresponding authors at: Wuxi School of Medicine, Jiangnan University, Wuxi 214122, P R China (C. Yu) and NHC Key Laboratory of Nuclear Medicine, Jiangsu Key Laboratory of Molecular Nuclear Medicine, Jiangsu Institute of Nuclear Medicine, Wuxi 214063, P. R. China (J. Lin).

E-mails: ycj_wxd1978@163.com (C. Yu) or linjianguo@jsinm.org (J. Lin) 


\section{Contents:}

Section 1: all ESI-MS data.

Section 2: all HPLC traces data.

Section 3: ${ }^{1} \mathrm{H}$ and ${ }^{13} \mathrm{C}$ spectra of non-radioactive compound GLNTGT.

Section 4: The UV data in radiolabeling of ${ }^{18} \mathrm{~F}$-GLNTGT.

Section 5: Result of in vitro CT contrast experiment of non-radioactive compound GLNTGT.

Section 6: PET imaging of ${ }^{18} \mathrm{~F}-\mathrm{AlF}-\mathrm{NOTA}-\mathrm{RGD}_{2}$.

Section 7: Analysis and Preparation HPLC methods. 


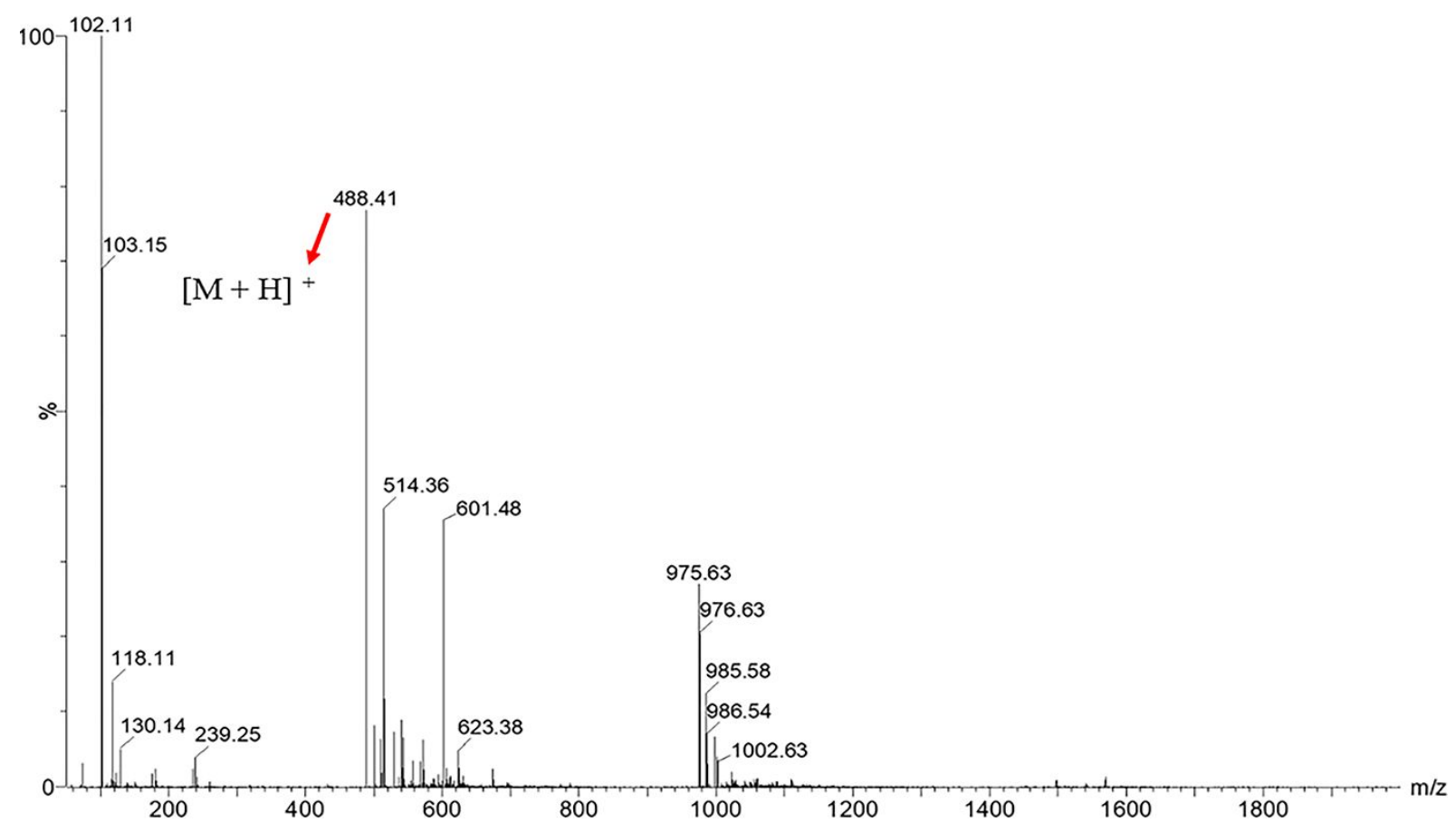

Figure S1. ESI-MS of intermediate A.

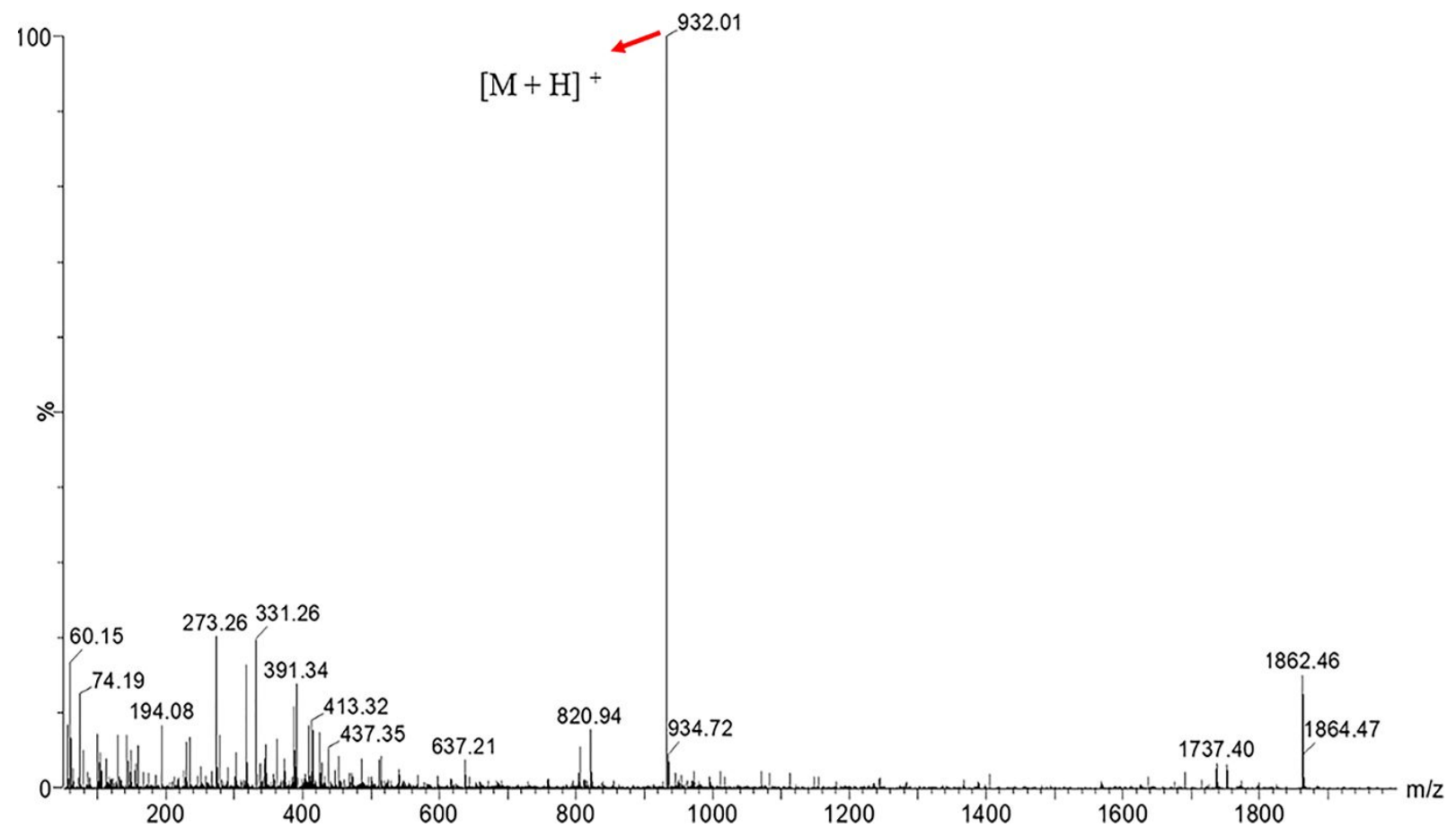

Figure S2. ESI-MS of intermediate B. 


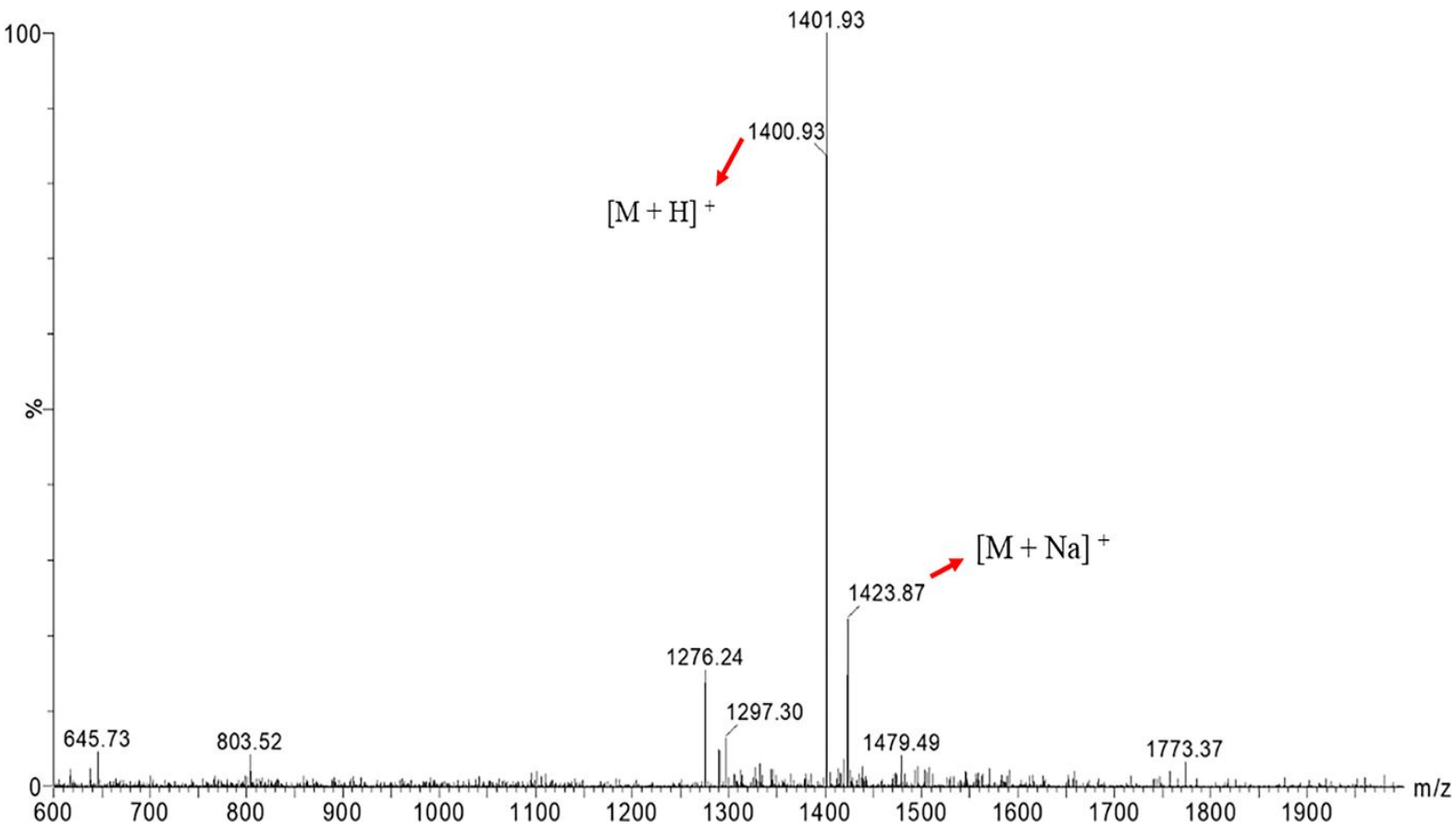

Figure S3. ESI-MS of compound 1.

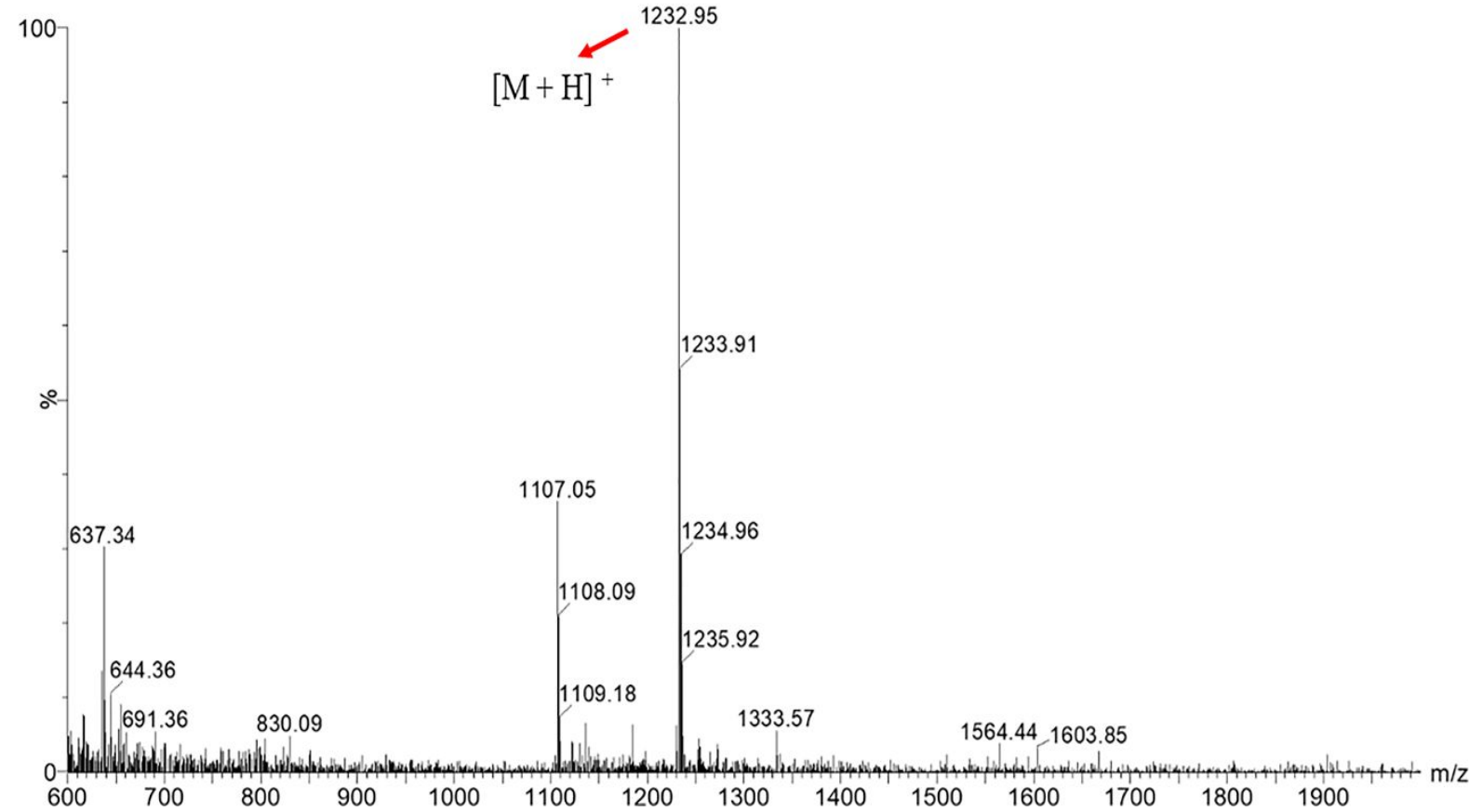

Figure S4. ESI-MS of compound 2. 


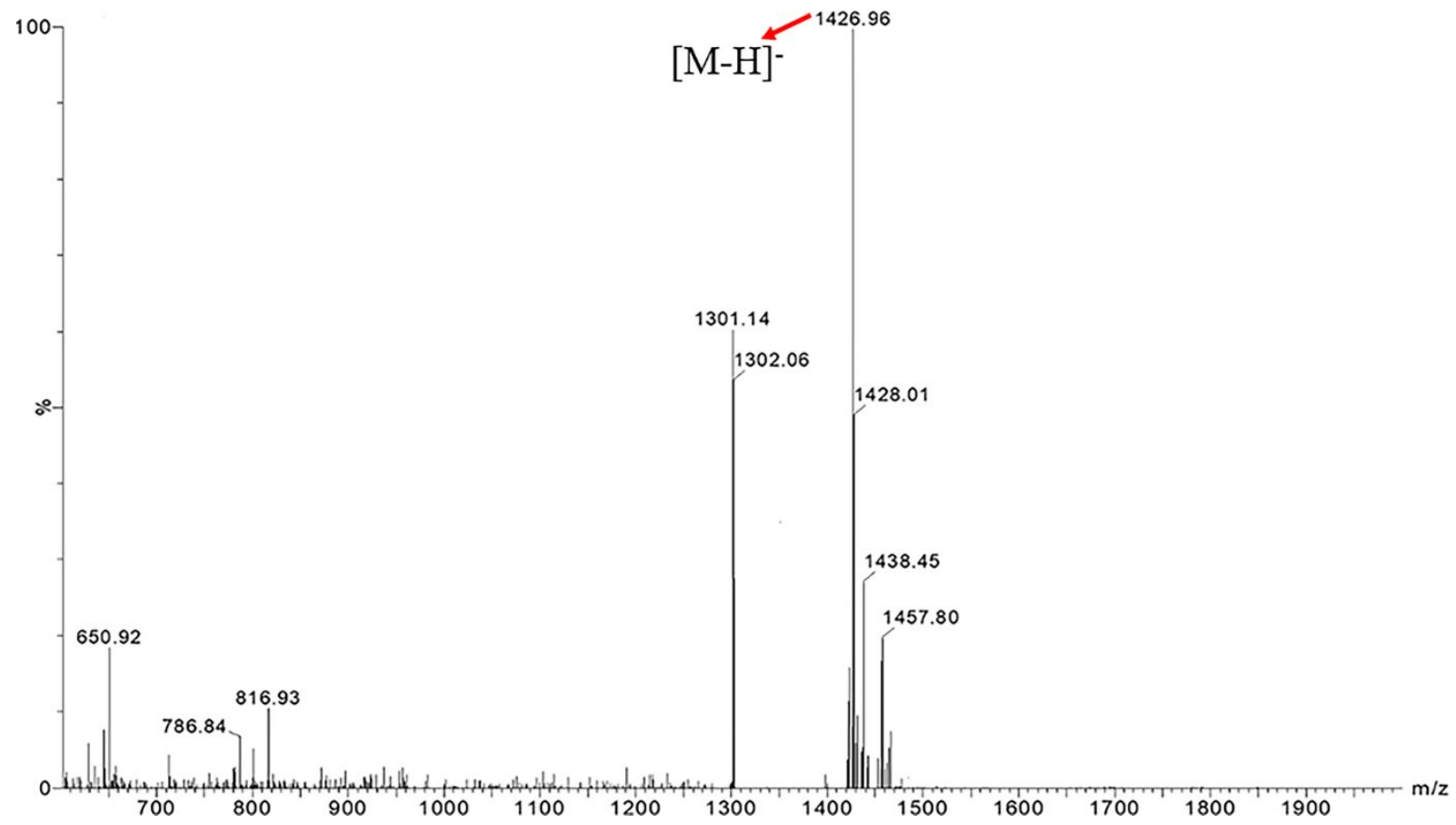

Figure S5. ESI-MS of non-radioactive compound GLNTGT.

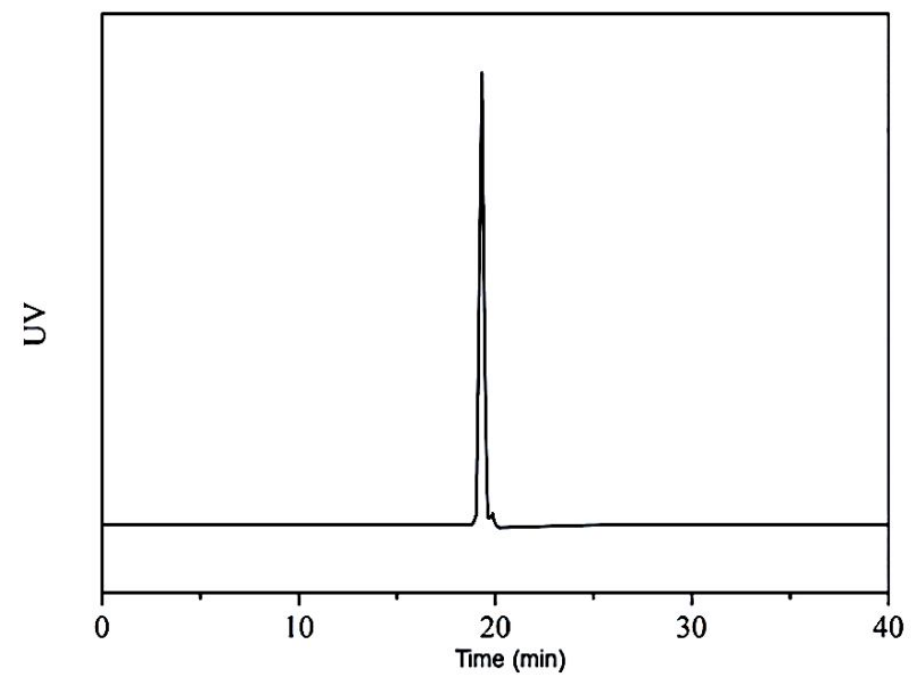

Figure S6. HPLC trace for intermediate B. 


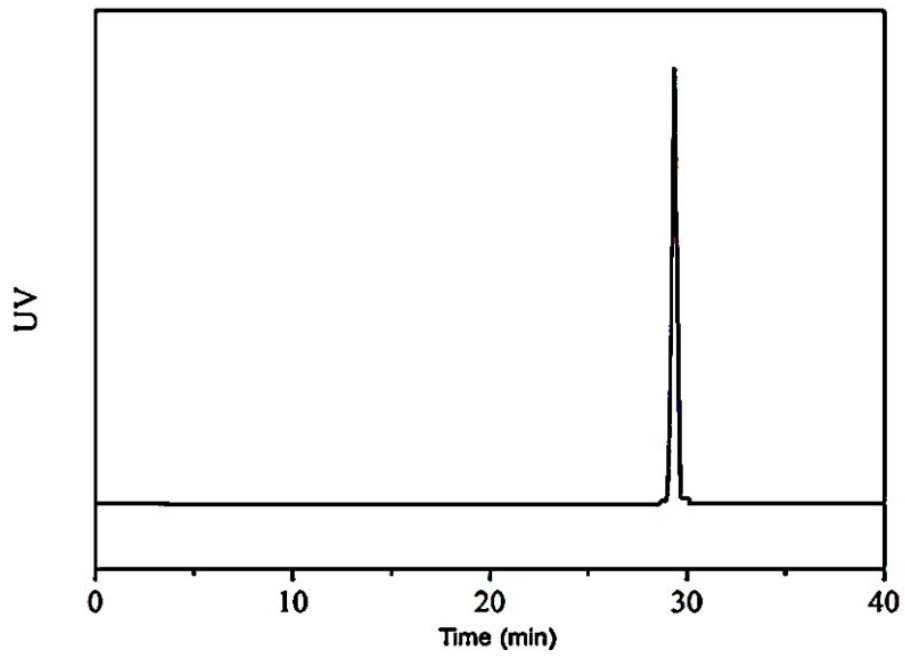

Figure S7. HPLC trace for compound 1.

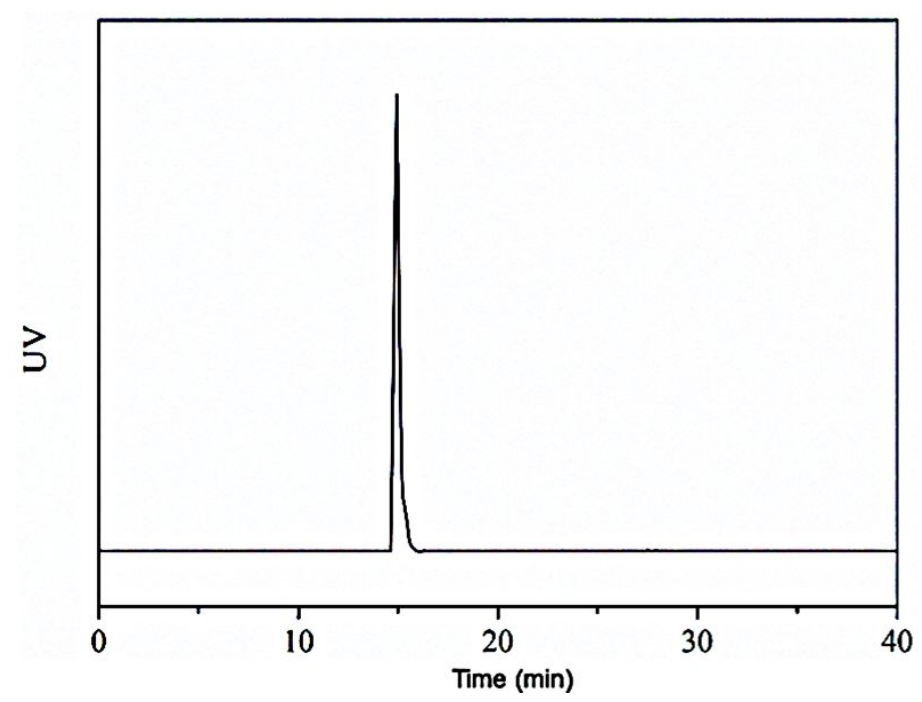

Figure S8. HPLC trace for compound 2. 


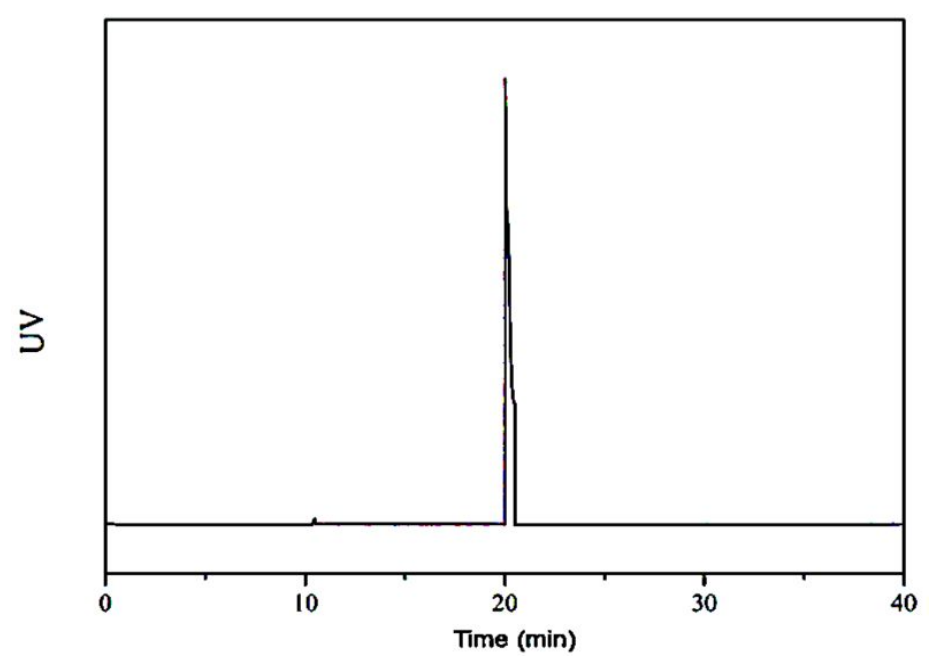

Figure S9. HPLC trace for non-radioactive compound GLNTGT.

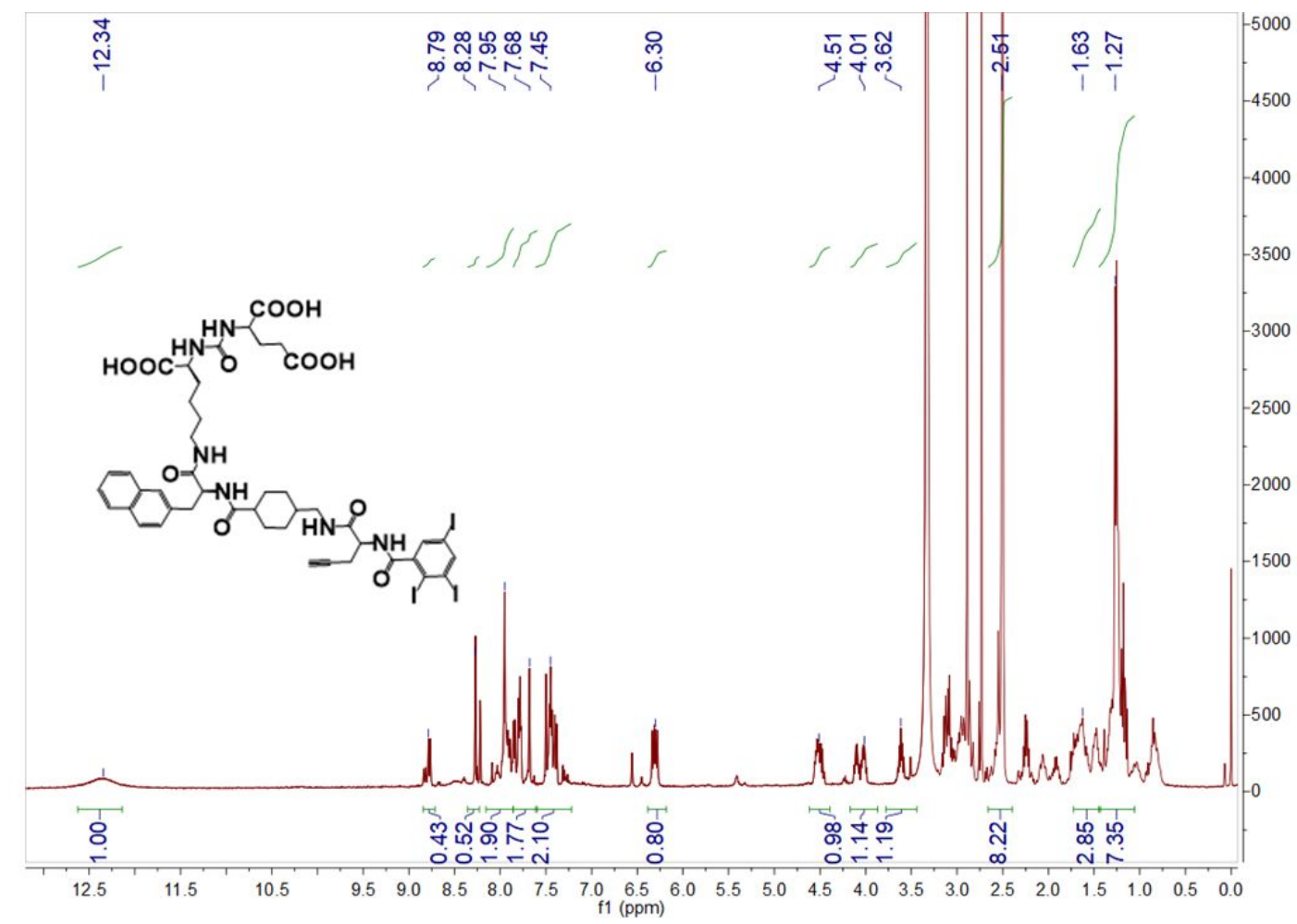

Figure S10. ${ }^{1} \mathrm{H}$ NMR spectra of non-radioactive compound GLNTGT. 


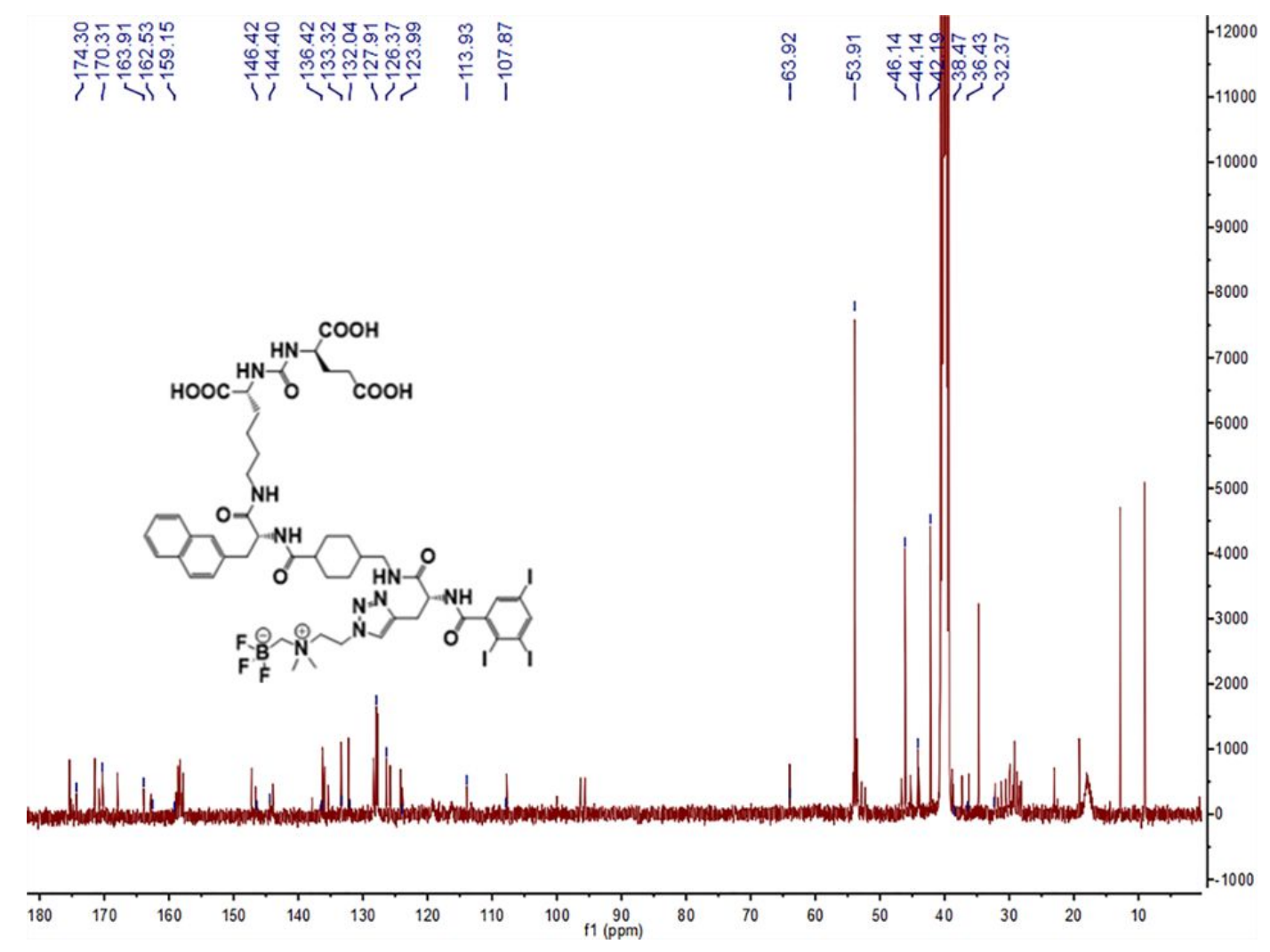

Figure S11. ${ }^{13} \mathrm{C}$ NMR spectra of non-radioactive compound GLNTGT.

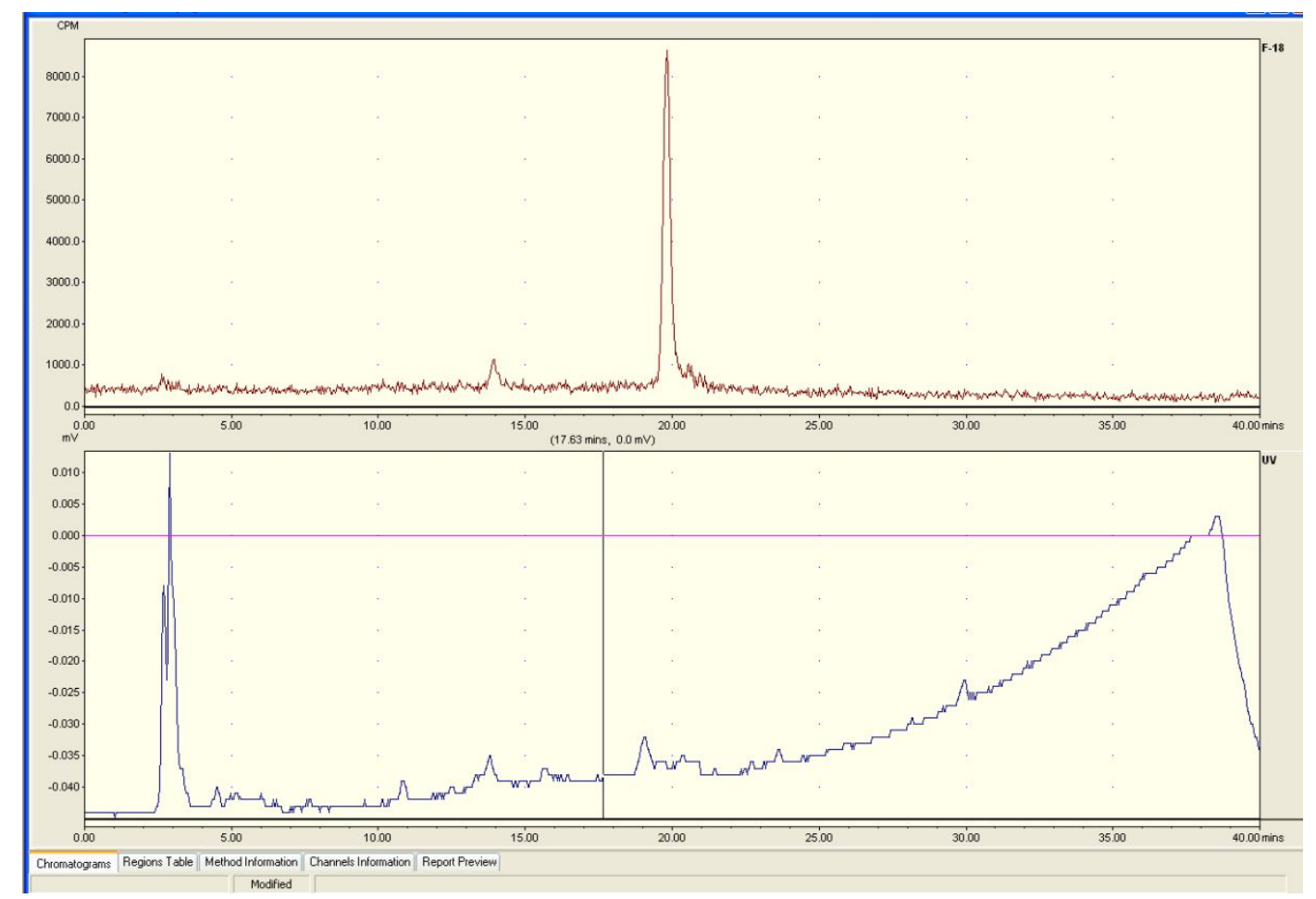

Figure S12. The UV data in radiolabeling of ${ }^{18} \mathrm{~F}-\mathrm{GLNTGT}$. 


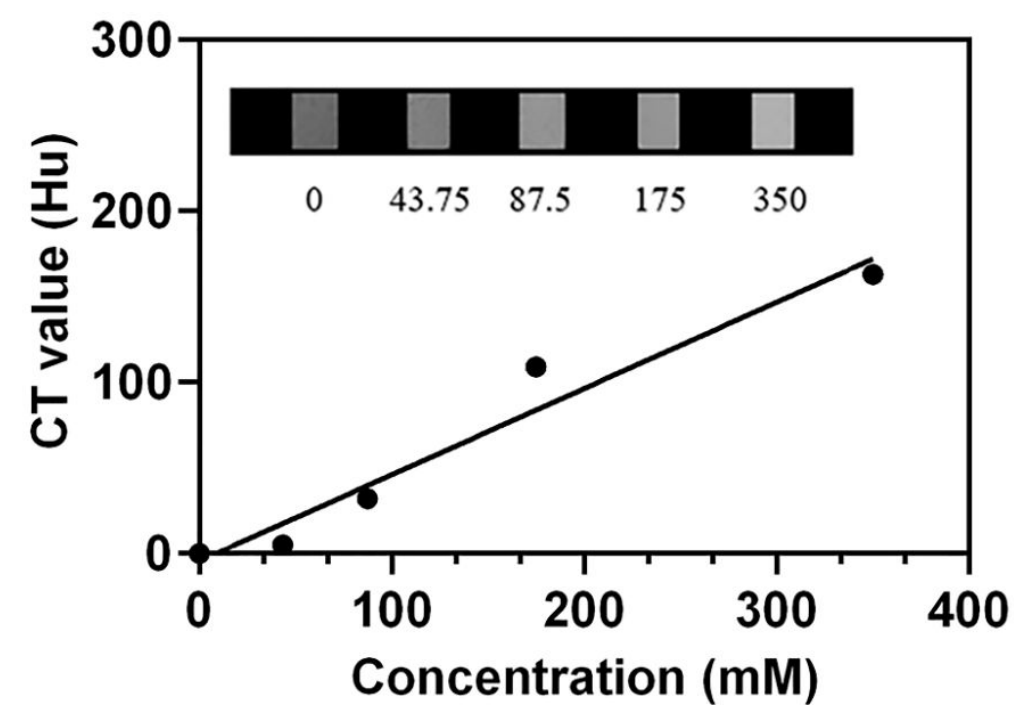

Figure S13. Result of in vitro CT contrast experiment of non-radioactive compound GLNTGT.

(a)

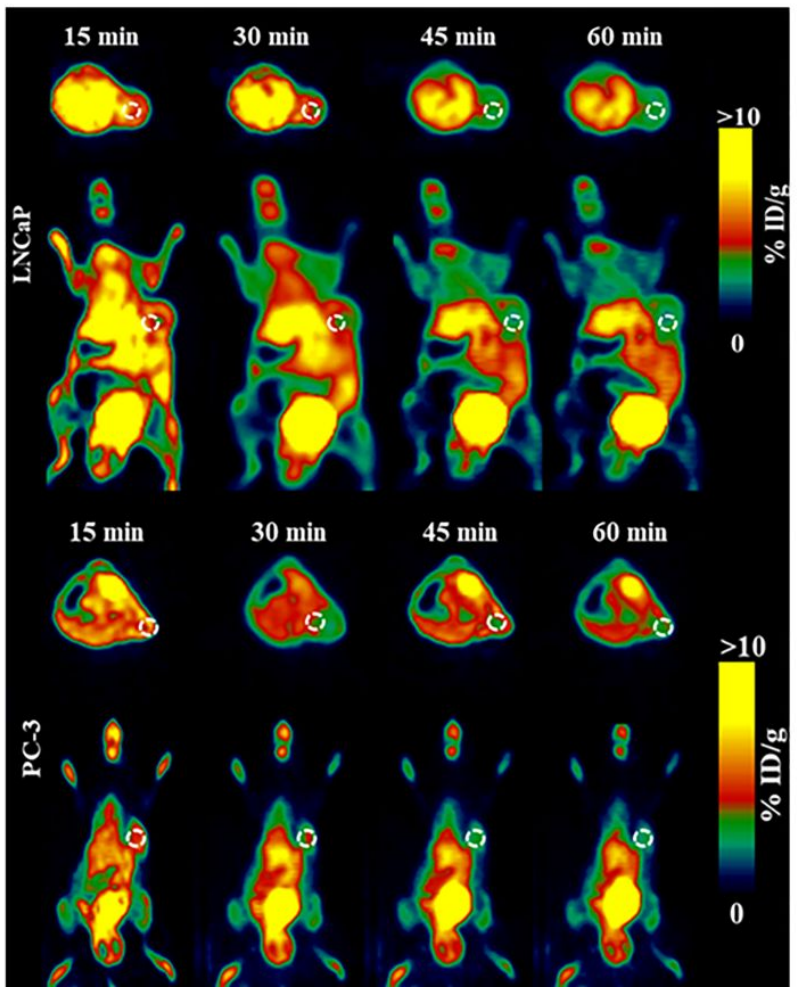

(b)

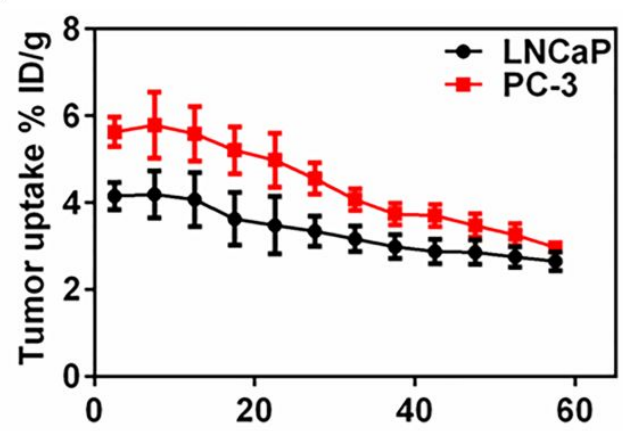

(c)

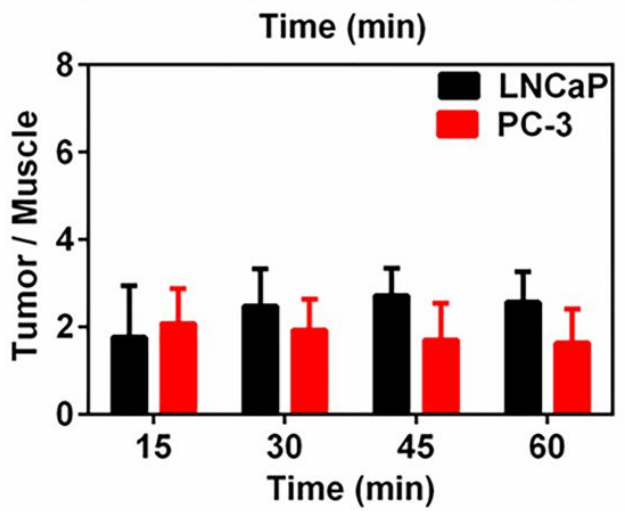

Figure S14. PET dynamic imaging in $60 \mathrm{~min}$. The xenograft tumor-bearing nude mice were

fixed and anesthetized ( $2 \%$ isoflurane mixed with oxygen), and then ${ }^{18} \mathrm{~F}-\mathrm{AlF}-\mathrm{NOTA}-\mathrm{RGD}_{2}$

(5.4-5.7 MBq) was injected by tail vein. (a) PET dynamic imaging in $60 \mathrm{~min}$ of mice with the 
injection of ${ }^{18} \mathrm{~F}-\mathrm{AlF}-\mathrm{NOTA}-\mathrm{RGD}_{2}$; (b) The average tumor uptake of the tracer ${ }^{18} \mathrm{~F}-\mathrm{AlF}-\mathrm{NOTA}-\mathrm{RGD}_{2}$ in the whole tumor region of interest of $\mathrm{LNCaP}$ tumors and PC-3 tumors; (c) The T/M ratio of ${ }^{18} \mathrm{~F}-\mathrm{AlF}-\mathrm{NOTA}-\mathrm{RGD}_{2}$ in $\mathrm{LNCaP}$ tumors and PC-3 tumors. Data were preformed mean $\pm \mathrm{SD}$ of $\mathrm{n}=3$ mice/group ( $*, P<0.05, * *, P<0.01, * * *, P<0.001)$.

Table S1. HPLC analysis method of non-radioactive compound GLNTGT and ${ }^{18} \mathrm{~F}$-GLNTGT.

\begin{tabular}{cccc}
\hline & $\begin{array}{c}\text { Flow rate } \\
(\mathrm{min} / \mathrm{mL})\end{array}$ & $\begin{array}{c}\text { A phase }(\%) \\
(0.1 \% \text { TFA of water })\end{array}$ & $\begin{array}{c}\text { B phase }(\%) \\
(0.1 \% \text { TFA of acetonitrile })\end{array}$ \\
\hline $0 \mathrm{~min}$ & 1 & 60 & 40 \\
$3 \mathrm{~min}$ & 1 & 60 & 40 \\
$35 \mathrm{~min}$ & 1 & 0 & 100 \\
$40 \mathrm{~min}$ & 1 & 60 & 40 \\
\hline
\end{tabular}

Table S2. Semi-Preparative HPLC method of non-radioactive compound GLNTGT.

\begin{tabular}{cccc}
\hline & $\begin{array}{c}\text { Flow rate } \\
(\mathrm{min} / \mathrm{mL})\end{array}$ & $\begin{array}{c}\text { A phase }(\%) \\
(0.1 \% \text { TFA of water })\end{array}$ & $\begin{array}{c}\text { B phase }(\%) \\
(0.1 \% \text { TFA of acetonitrile })\end{array}$ \\
\hline 0 min & 3 & 60 & 40 \\
3 min & 3 & 60 & 40 \\
35 min & 3 & 0 & 100 \\
40 min & 3 & 60 & 40 \\
\hline
\end{tabular}

